\title{
CES
}

COOPERATIVISMO E ECONOMÍA SOCIAL

Núm. 40 (2017-2018), páxs. 229-235

ISSN: $1130-2682$

\section{DISTINÇÃO ENTRE ATIVIDADES PRINCIPAIS E SECUNDÁRIAS E SUA RELEVÂNCIA EM SEDE DE IMPOSTO PATRIMONIAL NAS ENTIDADES SEM FINS LUCRATIVOS. COMENTÁRIO À SENTENÇA DO SUPREMO TRIBUNAL ADMINISTRATIVO, SEGUNDA SECÇÃO, DE 22 DE FEVEREIRO DE 2017, PROCESSO N. ${ }^{\circ} 1658 / 15$}

DIFFERENTIATION BETWEEN PRIMARY AND SECONDARY ACTIVITIES BY NON-PROFIT ENTITIES AND ITS RELEVANCE IN TERMS OF CAPITAL TAXES. COMMENTARY ON THE SENTENCE OF THE SUPREME ADMINISTRATIVE COURT, SECOND SECTION, OF FEBRUARY 22, 2017, PROCEDURE N. ${ }^{\circ} 1658 / 15$

NinA AguiaR*

0 Professora adjunta de Direito Fiscal e Direito Comercial no Instituto Politécnico de Bragança. Campus de Santa Apolónia, 5300-253, Bragança. Correio eletrónico: naguiar@ipb.pt 



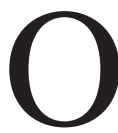
presente comentário tem como objeto a sentença do Supremo Tribunal Administrativo, Segunda Secção, de 22 de fevereiro de 2017, proferida no processo de recurso 1658/15, interposto contra o acórdão do Tribunal Central Administrativo-Norte datado de 3 de Julho de 2015, no qual se concedeu provimento ao recurso deduzido, pela Autoridade Tributária e Aduaneira, da decisão do Tribunal Administrativo e Fiscal de Aveiro datada de 30 de Dezembro de 2014, que julgou procedente a ação administrativa especial, deduzida no seguimento do pedido de anulação do ato de indeferimento de recurso hierárquico, praticado pela Subdiretora-Geral dos Impostos, relativo a benefício fiscal consistente na isenção de Imposto Municipal sobre Imóveis de prédio urbano.

O litígio entre o sujeito passivo, a Caixa Económica Montepio Geral, e a Administração Tributária diz respeito à interpretação de duas normas de isenção fiscal que eximem de Imposto Municipal sobre Imóveis as pessoas coletivas de utilidade pública, quanto aos prédios ou parte de prédios destinados à realização dos seus fins.

Por trás da questão puramente técnica da aplicabilidade da norma ao caso concreto, como veremos, encontra-se uma problemática de âmbito mais alargado, que diz respeito à delimitação das atividades das pessoas coletivas de utilidade que devem beneficiar das isenções e outros benefícios fiscais que o legislador lhes concede em razão dessa mesma utilidade pública, quando tal delimitação deva ser feita, como é o caso, em razão da afetação aos fins da pessoa coletiva.

\section{Sobre o estatuto de Utilidade Pública E os "Fins" Da ENTIDADE SUJEITO PASSIVO}

A Caixa Económica Montepio Geral (CEMG), sujeito passivo da relação jurídico-tributária controvertida no processo em causa, é uma caixa económica bancária, criada em 1844, revestindo atualmente a forma de sociedade anónima, pois é essa a forma jurídica exigida pela legislação vigente relativa à atividade bancária.

A CEMG tem, no entanto, como particularidade, o facto de ser uma "entidade anexa" de uma outra pessoa coletiva, o Montepio Geral - Associação Mutualista. Esta associação, legalmente constituída em 1840, detém por sua vez o estatuto de Instituição Particular de Solidariedade Social (IPSS). ${ }^{1}$ Trata-se de um estatuto legal atribuído exclusivamente a pessoas coletivas sem fins lucrativos, o que significa que dele ficarão sempre excluídas as sociedades, e apenas dele podendo gozar

1 O estatuto de "instituição particular de solidariedade social” foi inicialmente instituído pelo Decreto-Lei n. ${ }^{\circ} 119 / 83$, de 25 de fevereiro, republicado pelo Decreto-Lei n. ${ }^{\circ}$ 172-A/2014 de 14 de novembro. 
as associações, as fundações e as cooperativas, mas neste último caso apenas as que se dediquem às atividades prevista na lei que institui o estatuto.

As instituições particulares de solidariedade social (IPSS) têm como fim "dar expressão organizada ao dever moral de Justiça e de solidariedade" e terão que desenvolver, a título principal, uma ou várias das seguintes atividades: ${ }^{3}$ a) Apoio à infância e juventude, incluindo as crianças e jovens em perigo; b) Apoio à família; c) Apoio às pessoas idosas; d) Apoio às pessoas com deficiência e incapacidade; e) Apoio à integração social e comunitária; f) Proteção social dos cidadãos nas eventualidades da doença, velhice, invalidez e morte, bem como em todas as situações de falta ou diminuição de meios de subsistência ou de capacidade para o trabalho; g) Prevenção, promoção e proteção da saúde, nomeadamente através da prestação de cuidados de medicina preventiva, curativa e de reabilitação e assistência medicamentosa; h) Educação e formação profissional dos cidadãos; i) Resolução dos problemas habitacionais das populações; j) Outras respostas sociais não incluídas nas alíneas anteriores, desde que contribuam para a efetivação dos direitos sociais dos cidadãos. De onde se pode concluir que IPSS têm sempre como objeto o desenvolvimento direto e a título principal, sem fins lucrativos, de atividades de caráter solidário ou de apoio social.

Contudo, as IPSS podem também desenvolver "atividades de natureza instrumental relativamente aos fins não lucrativos", podendo fazê-lo através de "outras entidades por elas criadas, mesmo que em parceria e cujos resultados económicos contribuam exclusivamente para o financiamento da concretização daqueles fins." 4

Ora, precisamente, este era, e é ainda no momento atual, o caso da Caixa Económica Montepio Geral, SA. Tendo como objeto a atividade bancária, atividade que desenvolve em termos em tudo semelhantes às de qualquer outra entidade financeira, ela foi criada desde o seu início como uma "entidade anexa" do Montepio Geral - Associação Mutualista, tendo em relação aos fins desta última uma função instrumental, nos termos do artigo $3^{\circ} \mathrm{n}^{\circ} 1$ dos Estatutos do Montepio Geral - Associação Mutualista, que dispunha então: "o Montepio Geral, para auxiliar a realização dos seus fins: "a) Dispõe de uma caixa económica anexa, com personalidade jurídica e estatutos próprios, denominada Caixa Económica Montepio Geral".

Tal função instrumental traduz-se, em termos práticos, à data tal como hoje, na obrigatoriedade de entregar os seus resultados, apurados em cada exercício, predominantemente, ao Montepio Geral - Associação Mutualista, sua entidade mãe.

\footnotetext{
2 Artigo $1^{\circ}, n^{\circ} 1$ do Estatuto das Instituições Particulares de Solidariedade Social.

3 Artigo $1^{\circ}$-A do Estatuto das Instituições Particulares de Solidariedade Social.

${ }^{4}$ Artigo $1^{\circ}-\mathrm{B}, \mathrm{n}^{\mathrm{o}} 2$ do Estatuto das Instituições Particulares de Solidariedade Social.
} 
Com efeito, nos termos dos artigos $4^{\circ}$ e $5^{\circ}$ dos Estatutos da Caixa Económica Montepio Geral vigentes desde 1 de agosto de 1999, a mesma foi constituída “com a finalidade de pôr à disposição do Montepio Geral os resultados dos seus exercícios, feitas as deduções estatutariamente previstas, para que este os aplique na satisfação dos seus fins, estando anexa ao Montepio Geral, seu fundador."

Em consonância com este perfil estatutário, nos termos do artigo $36^{\circ}$ dos mesmos Estatutos, os resultados da Caixa Económica apurados em cada exercício teriam (à data) a seguinte afectação: “um mínimo de $20 \%$ para a reserva legal, um mínimo de 5\% para a reserva especial, as importâncias necessárias para outras reservas e o remanescente para o Montepio Geral."

Esta caracterização da relação entre a Caixa Económica Montepio Geral (CEMG) e a sua entidade mãe é a nosso ver o elemento chave de toda a questão em juízo. Estamos perante uma pessoa coletiva que tem fins lucrativos quando considerada isoladamente, ie que não sofre qualquer limitação ao exercício da sua atividade, nomeadamente quanto à prossecução do lucro através da mesma, em relação a qualquer outra entidade do mesmo ramo. Ela só tem o estatuto de utilidade pública porque está vinculada a afetar a maior parte dos seus lucros a uma Instituição Particular de Solidariedade Social. Cabe notar que a CEMG só pode deter na atualidade o estatuto de pessoa coletiva de utilidade pública, hoje, porque este lhe foi outorgado anteriormente a 1977, uma vez que o estatuto de utilidade pública está na atualidade reservado a pessoas coletivas que revistam a forma de associação ou de fundação. ${ }^{5}$ Assim, e resumindo, a utilidade pública da CEMG provém ou está ligada ao facto de ela, através de uma atividade lucrativa, gerar lucros que servem para financiar uma entidade sem fins lucrativos. Mas além disso, como vem a defender a Recorrente nos autos, devido a essa ligação institucional, ele existe para gerar rendimentos para a entidade bem, sendo então defensável, como faz a própria, que são esses os seus fins, para efeitos de aplicação da norma fiscal de isenção.

\section{A RELAÇÃO JURÍDICO-TRIBUTÁRIA CONTROVERTIDA}

A CEMG era detentora, em 2012, do direito de propriedade de um imóvel urbano que não se encontrava afeto à atividade bancária, tendo a função que se designa na contabilidade atual como propriedade de investimento. A CEMG tinha intenção de o vender, a fim de realizar mais-valias, e enquanto tal não acontecesse mantinha-o arrendado, retirando daí rendas que engrossavam os seus resultados.

No processo debatia-se entre outros pontos e a par da questão substancial, um problema de sucessão de leis no tempo que aqui não cabe minuciar. A questão

5 De acordo com o artigo $1^{\circ}$ do Decreto-Lei n. ${ }^{\circ}$ 391/2007 de 13 de Dezembro, que institui o regime das entidades de utilidade pública. 
principal, porém, é que uma das normas em concurso (o artigo $1^{\circ}$, al. d) da Lei n. ${ }^{\circ}$ 151/99, de 14 de Setembro, lei esta especificamente aplicável às entidades sem fins lucrativos) estabelecia uma isenção de imposto sobre imóveis que fossem prédios urbanos e que se provasse serem destinados à realização dos fins estatutários da pessoa coletiva de utilidade pública. Enquanto o Estatuto dos Benefícios Fiscais ${ }^{6}$, já vigente em 2012, dispunha e dispõe no seu artigo $44^{\circ}, n^{\circ} 1$, al. e), que "estão isentas de imposto municipal sobre imóveis as pessoas coletivas de utilidade pública administrativa e as de mera utilidade pública, quanto aos prédios ou parte de prédios destinados diretamente à realização dos seus fins.

A Autoridade Tributária considerou que só a segunda norma era aplicável ao caso, do ponto de vista da sucessão das leis no tempo, e sendo assim não havia lugar a isenção, pois o prédio em causa propriedade da CEMG, ao ter uma no património caixa económica uma função de propriedade de investimento, não estava diretamente destinado aos fins estatutários da entidade sujeito passivo. Esta, por seu turno, defendia, por um lado, que a norma aplicável era a primeira e, por outro lado, que o prédio em questão estava destinado aos seus fins estatutários, uma vez que o rendimento dele proveniente iria ser atribuído ao Montepio Geral - Associação Mutualista.

O Supremo Tribunal Administrativo terminaria por reduzir o seu veredito à questão da sucessão temporal das normas, concluindo que a norma de isenção do artigo $1^{\circ}$, al. d) da Lei n. ${ }^{\circ} 151 / 99$ estava efetivamente em vigor, ordenando assim à Administração Tributária reapreciar a questão à luz deste normativo, e com isso não se pronunciando o Tribunal sobre a questão de fundo que era a de saber se um imóvel afetado a locação ainda está, na medida em que gera rendas que são posteriormente entregues à entidade mãe, dentro dos fins estatutários da entidade subsidiária.

Sobre esta mesma questão de fundo, e com os mesmos intervenientes, contudo, pronunciou-se num outro recurso o Tribunal Central Administrativo-Norte ( $2^{\text {a }}$ Secção, Recurso no 780/13.3BEAVR, acórdão de 26-11-2015). Ao contrário do anterior, este Tribunal solveu a questão da sucessão de leis no sentido de que o artigo $1^{\circ}$, al. d) da Lei n. ${ }^{\circ} 151 / 99$ não está em vigor e que a norma aplicável é a al. e) do artigo $44^{\circ}$ do EBF. Fechada esta questão, o Tribunal solucionou a questão de fundo, concluindo que "o benefício é concedido quando os prédios estão afectos à realização dos fins da pessoa coletiva de utilidade pública e não quando apenas os rendimentos estejam afectos a esses fins". Continua ainda afirmando que tem que existir uma relação direta entre o destino dos prédios e os fins prosseguidos pela pessoa coletiva. Sendo que essa relação só é direta quando resulta da própria afectação ou utilização do prédio. Quando são os rendimentos do prédio que estão

\footnotetext{
${ }^{6}$ O Estatuto dos Benefícios Fiscais foi inicialmente aprovado pelo Decreto-Lei n. ${ }^{\circ} 215 / 89$, de 1 de Julho, tendo sido revisto e republicado pelo Decreto-Lei n. ${ }^{\circ}$ 108/2008, de 26 de junho.
} 
afectos a utilidade pública da pessoa coletiva, a relação entre o prédio e os fins de utilidade pública não é direta, mas indireta.

O Supremo Tribunal Administrativo, por sua vez, já sancionou recentemente este entendimento, apenas no que diz respeito à interpretação da al. e) do artigo $44^{\circ}$ do EBF, em acórdão de 3 de outubro de 2018 (processo no 0734/13.0BEPNF 0922/16), em que se pronunciou no sentido de que "as situações abrangidas por este artigo $44^{\circ}$, n. $^{\circ} 1$, al. e) do EBF respeitam àqueles prédios que estão diretamente afectos aos fins estatutários da pessoa coletiva, v.g. (..) os necessários à instalação da sua sede, delegações e serviços indispensáveis aos fins estatutários".

\section{Conclusão}

A questão de fundo descrita neste comentário é de grande atualidade e transcende amplamente o caso concreto da CEMG, em vista da alteração do regime das Instituições Particulares de Solidariedade Social que entrou em vigor em 2014, e que prevê que estas possam, com grande amplitude, criar entidades subsidiárias, tando de fins lucrativos como de fins não lucrativos.

Com efeito, dispõe o ${ }^{\circ} 2$ do artigo $1^{\circ}$-B do Regime das Instituições Particulares de Solidariedade Social que "as instituições podem ainda desenvolver atividades de natureza instrumental relativamente aos fins não lucrativos, ainda que desenvolvidos por outras entidades por elas criadas, mesmo que em parceria e cujos resultados económicos contribuam exclusivamente para o financiamento da concretização daqueles fins."

O legislador português não esclareceu até ao momento qual é o regime fiscal das entidades lucrativas subsidiárias das IPSS. Os acórdãos citados mostram existir a necessidade, desde logo, de distinguir se essas entidades têm ou não o estatuto de utilidade pública. Expõem igualmente a urgência de adaptar as disposições do EBF ao novo regime das IPSS, de modo a contemplar as entidades subsidiárias das IPSS que, com ou sem estatuto de utilidade pública, desenvolvam atividades lucrativas, com o objetivo de financiar as atividades das suas entidades mãe. 